\title{
Percursos Corpo-Experienciais a partir do Bebop-de-Lugar: sentidos espaciais na Galeria Cosmococa no Instituto Inhotim de Arte Contemporânea
}

\author{
Body-Experiential Pathways trough Place-Bebop: spatial senses in Galeria \\ Cosmococa at Instituto Inhotim de Arte Contemporânea
} Caminos Cuerpo-Experienciales a partir del Bepop-de-Lugar: sentidos espaciales de
Galeria Cosmococa en el Instituto Inhotim de Arte Contemporânea

\author{
Carlos Roberto Bernardes de Souza Júnior ${ }^{1}$ \\ https://orcid.org/0000-0003-2630-657X
}

\begin{abstract}
RESUMO: Reconstruídas no Instituto Inhotim de Arte Contemporânea conforme concebidas por Hélio Oiticica e Nevile d'Almeida, as cinco cosmococas que compõem a Galeria Cosmococa oferecem diferentes experiências imersivas espaço-sensoriais. Por meio da perspectiva da fenomenologia existencialista Merleau-Pontiana, o ensaio objetiva desvelar como as cosmococas podem colaborar para a compreensão da experiência efêmera e corporificada de lugar vivenciada pelos sujeitos no seu cotidiano. Em transcendência ao conceito de balé-do-lugar proposto por Seamon, a experiência entrópica de imersão na obra indica uma temporalidade transitória que cristaliza um bebop-de-lugar. Ela implica em formas pelas quais os encontros e movimentos entre sujeitos e lugares ganham contornos complexos na medida em que o acaso e o imprevisto se espacializam. As instalações explicitam micro-dinâmicas de lugar que se desvelam no horizonte temporal do instante fenomênico sintetizado no bebop-de-lugar.
\end{abstract}

PALAVRAS-CHAVE: Corporeidade. Balé-do-lugar. Bebop-de-lugar. Movimento. Geografia e Arte.

\begin{abstract}
Rebuilt in the "Instituto Inhotim de Arte Contemporânea" as conceived by Hélio Oiticica and Neville d'Almeida, the five cosmococas that compose "Galeria Cosmococa" are immersive spatialsensorial experiences. The essay intends to, through a Merleau-Pontian existentialist phenomenological perspective, decipher how the cosmococas can open up geographical comprehension of ephemeral and bodily experience of place lived by subjects in their daily lives. In transcendence to Seamon's concept of place-ballet, the entropic experience of immersion in the artwork indicates a transitory temporality that crystalizes on place-bebop. Cosmococas implicate in way by which subject-place encounters and movements gain complex outlines in the spatialization of chance and unpredictability. The installations make explicit microdynamics of place that unravel in the phenomenal instant temporal horizon synthetized in place-ballet.
\end{abstract}

KEYWORDS: Corporeality. Place-ballet. Place-bebop. Movement. Geography and Art.

\footnotetext{
1 Doutorando do Programa de Pós-Graduação em Geografia do IESA/UFG. E-mail: carlosroberto2094@gmail.com.
} 
RESUMEN: Reconstruido en el "Instituto Inhotim de Arte Contemporânea" como concebidas por Hélio Oiticica y Nevile d'Almeida, las cinco cosmococas que componen "Galeria Cosmococa" ofrecen diferentes experiencias inmersivo-sensoriales en el espacio. A través de la perspectiva de la fenomenología existencialista de Merleau-Ponty, lo objetivo del estudio es conocer cómo las Cosmococas pueden contribuir a la comprensión de la experiencia efímera y encarnada de lugar experimentada por los sujetos en su vida cotidiana. En trascendencia al concepto del ballet-do-lugar propuesto por Seamon, la experiencia entrópica de inmersión en la obra de arte indica una temporalidad transitoria que cristaliza un bebop-de-lugar. Ellas indican formas en que las encuentros y movimientos entre los sujetos y lugares ganan contornos complejos en los cuales el oportuno e imprevisto se espacializam. Las instalaciones muestran micro-dinámicas de lugar que del horizonte temporal del instante fenomenal sintetizado en el bebop-de-lugar.

PALABRAS CLAVE: Corporeidad. Ballet-de-lugar. Bebop-de-lugar. Movimiento. Geografía y Arte.

\section{INTRODUÇÃO}

Hélio Oiticica foi um dos principais artistas brasileiros de arte contemporânea na segunda metade do século XX. Do final dos anos 1960 até seu falecimento em 1980, criou inúmeras e inovadoras instalações focadas na experimentação de formas, cores e experiências corporais (LAGO, 2011). Seu pioneirismo foi internacionalmente reconhecido em 1989, quando foi o principal artista da exposição Brazil Projects no Museum of Modern Art of New York (SARDENBERG, 2011).

Originalmente concebidas em parceria com Nevile d'Almeida e realizadas em menor escala no seu apartamento em Nova lorque na década de 1970, as cosmococas são cinco salas-instalações sensoriais. Elas expressam um período em que Oiticica morava ilegalmente nos Estados Unidos e era usuário de cocaína. Cada cosmococa aborda aspectos sensório-experienciais de sua situação utilizando objetos cotidianos, músicas e projeções. Somadas, formam um conjunto interativo que consegue imergir o espectador em um espaço que remete à psicodelia (TUNGA, 2011).

Atualmente reconstruídas na forma da Galeria Cosmococa no Instituto Inhotim de Arte Contemporânea em Brumadinho-MG, a forma atual foi constituída de acordo com a visão original do artista e as contribuições de Nevile d'Almeida. Ao imergir e transitar por cada cosmococa, é possível identificar uma experiência particular da relação entre o corpo e o espaço. Nessa conexão, costuram-se sentidos de lugar que surgem no instante situacional do encontro entre sujeito-obra. Em uma dinâmica de improviso e acaso, a geograficidade (DARDEL, 2011) da obra é arquitetada de uma maneira particular para cada pessoa que com ela interage. 
Ao explorar a potencialidade sensorial e espacial presente nessa instalação de arte contemporânea, é possível identificar aspectos particulares dos espaciais da percepção. Adota-se como pressuposto inicial o dinamismo inseparável sujeito-lugar presente no conceito de place-ballet, traduzido usualmente como balé-de-lugar ou dança de lugar, formulado pelo geógrafo humanista Seamon (1979, 2014), de modo a identificar como ele pode ser uma faísca inicial para entender os encontros e movimentos na obra.

Por meio da correlação de seu conceito com as experiências transitórias e dinâmicas corporais das cosmococas, pode-se decifrar como a experiência temporal do instante encadeia-se para a dinâmica transitória do bebop-de-lugar. Articulado à fenomenologia existencialista de Merleau-Ponty (2011, 2012, 2013, 2014), buscou-se desvelar como as Cosmococas podem colaborar para a compreensão da experiência efêmera e corporificada de lugar vivenciada pelos sujeitos no seu cotidiano.

Para tanto, houve empenho na execução de metodologias geográficas criativas embasadas centralmente nas propostas de Hawkins (2011, 2014). Como discorre a autora, as práticas artísticas podem contribuir sobremaneira para as Geografias Culturais contemporâneas, particularmente em sua preocupação recente com a corporeidade. Ao explorar esse campo, argumenta a autora, potencializa a capacidade de desvelar as experiências corporais e emotivas de espaço e lugar. (HAWKINS, 2014).

Foram realizados trabalhos de campo por meio dos quais pode-se imergir e experienciar as cinco instalações na galeria do Instituto Inhotim. Tal percurso foi informado na proposta de Hawkins (2014), na qual buscou-se efetivar uma prática aberta de exploração, imersão e observação nas instalações sem um roteiro pré-determinado. Em decorrência desse fator, ao longo do artigo as cinco cosmococas não aparecem em ordem numérica, mas em função de sua conexão significativa com o fluxo explicativo decorrente da experiência de lugar de cada obra. Também foi empregado o desenho de um mapa experiencial que sumariza a dinâmica de movimento e encontro espacial na obra. Em conjunto a esse processo, foi efetivada busca bibliográfica nos temas concernentes no campo da Geografia, Arte e Fenomenologia.

\section{EXPERIÊNCIAS DE LUGAR NA RELAÇÃO COM O LUGAR-OBRA DAS COSMOCOCAS}

Em transcendência à perspectiva contemplativa, a arte contemporânea é centrada no nexo da experiência do espectador (ARCHER, 2012; BUSKIRK, 2003). Nesse sentido, a compreensão das obras exige um processo imersivo pelo qual o sujeito interage ativamente com a espacialidade da arte. Os lugares-obras são núcleos relacionais por onde são reproduzidas múltiplas geografias sensíveis. 
A interação ativa com as obras de arte é a virtualidade pela qual um espaço é gerado. De acordo com Cobb (1973, p. 431, tradução livre) “[...] apreciação pura ou contemplação é um limitante no caso da existência humana. Até mesmo no caso de uma obra de arte, a relação de uma pessoa a ela raramente é meramente a de espectador". A relação com a arte é necessariamente uma atitude ativa.

Essas razões suscitam Hawkins (2011, p. 472, tradução livre) a afirmar que "[...] o que é claro é a necessidade de nós, como geógrafos, exploramos a arte não somente como um objeto 'terminado', mas pensar nas obras de arte como conjuntos de práticas, artefatos, performances e experiências". Uma perspectiva que compreenda a arte como processo implica no decifrar das situações no seio da dinâmica experiencial dos sujeitos. Esse entendimento perpassa pela noção de que os lugares-obras são criações que possibilitam determinados horizontes de mundo a emergirem.

Para Karjalainen (2012), os lugares são fenomenologicamente efetivados na condição de partes da realidade espacial dimensionadas pela intencionalidade humana. Os lugares resultam do engajamento com as espacialidades do mundo em que o ser habita. Lugar também pode ser um objeto ou uma coisa que tenha a dimensão espaço-apropriativa para sujeitos (TUAN, 2012, 2013).

Na perspectiva Merleau-Pontiana, como discorre Morris (2004, p. 122, tradução livre), "[...] a coisa me solicita como se ocupando seu próprio lugar, nas minhas explorações ela continua me puxando para manipula-la e explorar seu envelope". Ou seja, as próprias coisas têm seus lugares que agem como centros atrativos para a percepção e imaginação humana. Ainda que sejam seres em-si, sua substância está em constante interação com seres parasi.

Mais que algo inercial, as obras de arte são coisas que colocam em movimento diversas dinâmicas no horizonte da realidade. Ramírez (2010, p. 58, tradução livre, grifos no original) afirma que "[...] a arte cria tudo isso. Ela não representa nem nega a realidade, ela cria uma nova realidade". Ela não é apenas um cosmo reativo ao ser para-si que cria ela, mas é um em-si arquitetado com toda a virtualidade de uma realidade.

McDuffie (1995, p. 215, tradução livre) explica que "[...] para experienciar uma obra de arte como uma obra, nós precisamos nos abrir para seus conteúdos sensuais e imaginativos, seguir sua estrutura temporal e dar a ela credibilidade como tema de nossa atenção". É apenas ao permitir-se imergir no contexto de um determinado lugar-obra que é possível compreender sua estrutura espaço-temporal. Na relação sensível com seus conteúdos imaginativos e perceptíveis, o sujeito pode efetivamente conectar-se com a obra.

No Instituto Inhotim, a Galeria Cosmococa é um nodo significativo de experiências sensíveis por meio das quais os sujeitos se entrelaçam com a dinâmica lugarizada das obras. A galeria, onde se pode entrar apenas com pés descalços, é composta por 5 
cosmococas: obras que são ambientes imersivos onde o observador pode interagir com objetos dispostos pelos artistas. Com a luminosidade reduzida há sempre uma projeção que preenche as paredes. Cada cosmococa possui um ambiente musical que complementa o nexo da obra.

Elas são cosmos experienciais por meio dos quais aquele que nelas imerge entra em uma realidade libertadora de interação com a obra da forma que desejar. Tudo que está disposto pode ser tocado, manipulado e observado. É possível, esporadicamente, encontrar pessoas deitadas, sentadas ou lixando as unhas dentro das cosmococas. Cada uma delas, ao mesmo tempo, apresenta uma experiência diferente por meio da maneira como é composta.

Na Cosmococa 3 Mayleryn (Figura 1), o chão é coberto por um vinil transparente que, entremeado a temperatura do ambiente resulta em um piso gelado e suavemente escorregadio. As projeções pulsantes da imagem de Marlyn Monroe maquiada com um pó branco que remete a cocaína, ressaltam a dinâmica psicodélica recorrente nas cosmococas.

Figura 1 - Hélio Oiticica e Nevile D’Almeida - Cosmococa 3 Mayleryn (1973)

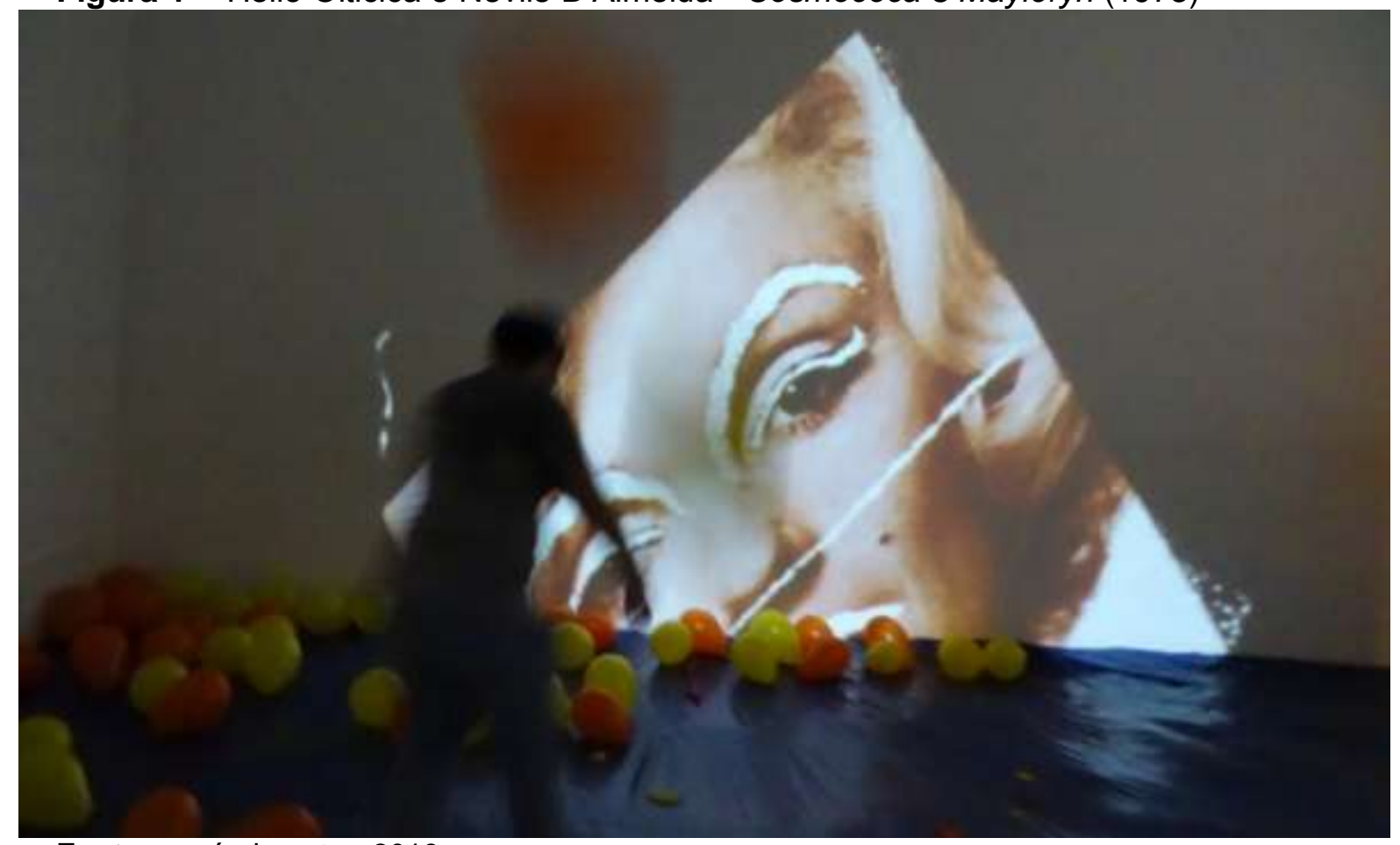

Fonte: o próprio autor, 2019.

Outro elemento fundamental é a perspectiva interacional com os balões. Eles estão espalhados pelo solo da sala de modo a convidar o visitante a interagir. Ao imergir na obra, o sujeito agarra, joga, estoura ou apenas segura algum balão. Os sujeitos podem interagir com ela individualmente ou coletivamente. Há múltiplas possibilidades de ações dentro dessa cosmococa. 
De acordo com Kaushik (2011, p. 11, tradução livre), "[...] o ser, descoberto pela obra de arte, dissolve a objetividade das coisas e suas determinações conceituais, e revela em seu lugar o momento em que ele realmente participa do espetáculo sensível - a participação secreta das coisas em uma harmonia desregulada". Nesse sentido, a experiência do lugarobra nessa cosmococa é uma participação em que o sujeito é dissolvido pelo espetáculo sensível de sua interação. No jogo harmônico, aquele que imerge e a espacialidade topológica da imersão se confundem.

Se, como discorre Seamon (2014, p. 11, tradução livre) "[...] fenomenologicamente, lugar não é o meio físico separado das pessoas associadas com ele, mas o indivisível e normalmente imperceptível fenômeno de pessoa-ou-pessoas-experienciando-lugar", consubstancializa-se que o lugar-obra da cosmococa é um fenômeno inseparável do sujeito nela imerso. É somente ao ser imersa que a obra se realiza enquanto um fenômeno de lugar. Sua espacialidade é tomada de sentido e substancializa-se na indivisibilidade com aquele que captura um balão ou se senta para observar as projeções nas paredes.

Como pondera Silva (1986, p. 98) “[...] o ser produz o lugar e é produzido por ele”. É por meio da experiência sensível e corporal no lugar chöréico da cosmococa que há consubstancialização de uma topologia. Essa, por sua vez, é uma produção que decorre tanto do lugar, na condição de Chöra e espacialidade artística, quanto do sujeito que nele imerge, produz um Topos reativo. O somatório desses dois elementos arquiteta efetivamente esse lugar-obra relevante.

Fenomenologicamente, isso condiz com a situação de reversibilidade entre os entes envolvidos nesse processo de lugarização no horizonte da interação. Como propõe DunphyBomfield (2007, p. 223, tradução livre), "[...] aquele que percebe e o percebido então interrelacionados em um processo dinâmico". É o circuito ativo da percepção (MERLEAUPONTY, 2011) que entrelaça o Ser ao lugar-obra. Na cosmococa, a psicodelia da experiência que abarca os cinco sentidos daquele que imerge ecoa em um processo que impele o sujeito a ter alguma reação à obra em que adentra.

Kaushik (2011, p. 9, tradução livre) explica que "[...] para Merleau-Ponty, existe um sentido no qual o objeto de arte em si mesmo possui uma expressividade que gera sentidos de forma que ele tem seus próprios aspectos temporais e espaciais que compõem seu próprio mundo". Como uma realidade, o lugar-obra é um cosmo denso por onde seu próprio mundo é que possibilita a imersão humana. A expressividade apresentada no seio das cosmococas reverbera esse sentido.

Ao concordar com Casey (1998, p. 235, tradução livre, grifo no original) "[...] um local onde não haja possibilidade de presença corporal humana, seja de fato ou por projeção imaginativa, não é lugar desde o começo", destaca-se que é necessária uma possibilidade interativa-perceptiva com o corpo sujeito para que o lugar seja significado. Nas obras- 
lugares das cosmococas, o contexto acional é tanto uma projeção imaginativa quanto um fato experiencial que ocorre por meio da imersão.

Em Cosmococa 2 Onobject (Figura 2) o sujeito é imerso em um ambiente mais escuro que os demais. O som que percorre o ambiente é uma experimentação sonora de Yoko Ono que utiliza de sons telefônicos. O piso é uma espuma profunda revestida por tecido em que cada passo se adentra no chão. Os objetos de espuma espalhados pela sala propiciam uma exploração dinâmica, assim como em Cosmococa 3 Mayleryn.

Figura 2 - Hélio Oiticica e Nevile D’Almeida - Cosmococa 2 Onobject [Detalhe] (1973)

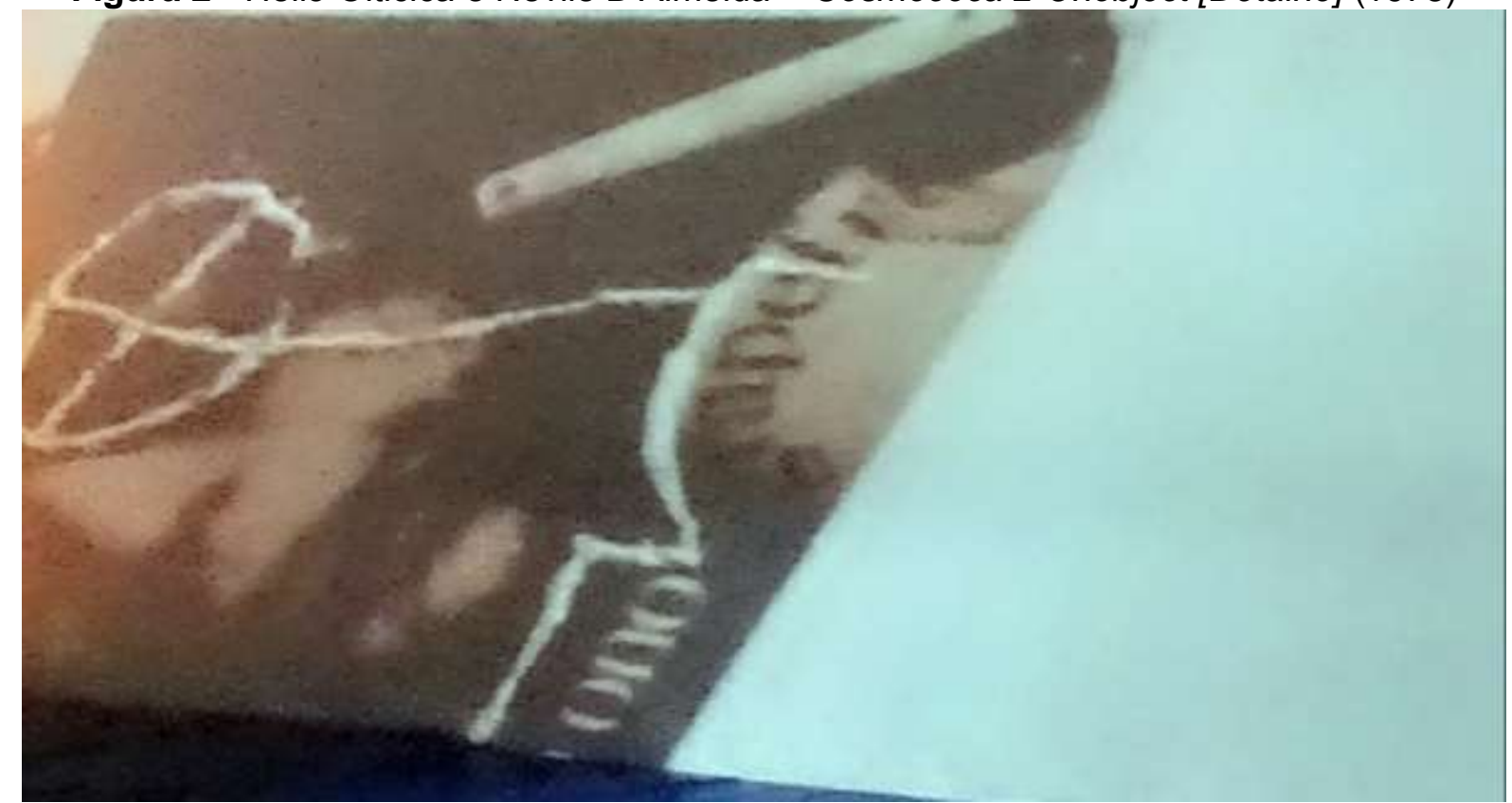

Fonte: o próprio autor, 2019.

A maciez almofadada da cosmococa 2 é contraposta à projeção constante da capa do livro Grapefruit de Yoko Ono (foco do detalhe da Figura 2). Em conjunto ao som, ele dita a tonalidade do engajamento nesse lugar-obra. Se, conforme sugerem Larsen e Johnson (2012, p. 633, tradução livre), "[...] lugar é como o mundo se apresenta, ser inevitavelmente requer um lugar, uma situação para sua apresentação", a situação de Onobject é uma imersão em uma imaginação de lugar permeado por fantasmas existenciais.

Tais fantasmas são o espectro experiencial de uma certa percepção sobre a espectralidade da confluência psicodélica entre a imagem sonora e visual de Yoko Ono e a experiência tátil da espuma. Ao sentar e sentir esse lugar-obra, há um princípio de fusão entre a situação existencial de presentificação do mundo da cosmococa e o sentido percebido por aquele que nela está imerso.

Como pondera Archer (2012, p. 236) "[...] a arte é um encontro contínuo e reflexivo com o mundo em que a obra de arte, longe de ser o ponto final desse processo, age como iniciador e ponto central da subseqüente investigação do significado". Nesse nexo, a 
imersão na Cosmococa 2 Onobject, assim como nas outras cosmococas, deve ser entendida como um processo experiencial. A investigação perceptiva realizada pelo corposujeito promove-se por meio do encontro sujeito-obra no cosmo do lugar.

No horizonte da percepção, as coisas e fenômenos da relação arte-sujeito-lugar vão se desvelando por meio da experiência. Kaushik (2011, p. 138, tradução livre) problematiza que "[...] o observador não pode esquecer, não pode deixar para trás, o período em que as coisas agora visíveis antes foram desnudadas, ainda antes nem mesmo eram coisas - 0 período em que foram instituídas". Aquilo que foi sentido incorpora-se no nexo geral de percepção daquele determinado lugar-obra. Nas cosmococas, cada situação experiencial é realizada no devir do circuito perceptivo do sujeito imerso.

Segundo Casey (2010, p. 2, tradução livre) "[...] o espectador, assim como o artista, é convidado a se engajar em uma atividade imaginativa na qual os conteúdos excedem as libertações da experiência perceptiva ordinária". Essa atividade arte-sujeito forma uma reversibilidade sensível na qual um se mistura com o outro. A amálgama gerada dessa relação é espacializada na corporeidade do ente perceptivo em seu entrelaçamento com a obra de arte.

Isso ocorre em decorrência do fato de que, como provoca Seamon (1979, p. 73, tradução livre), "[...] onde quer que formos, mesmo pelos mais curtos períodos de tempo, nós estabelecemos lugares por meio dos quais orientamos nosso mundo e nossas atividades espaciais". Mesmo no curto período de tempo em que pode ser realizada (ou estendida) o ingresso no mundo de cada cosmococa, ela causa um efeito significativo que leva o sujeito a (re)orientar-se espacialmente. Ao realizar essa ação, a percepção se lugariza, tanto de maneira chöréica quanto topológica, no âmago da relação sujeito-obra.

As cosmococas plasmam um nexo psicodélico que colabora para tal experiência dualizada apresentada. Nas figuras alusivas à cocaína que se misturam à musicalidade e ambiente da contracultura nos Estados Unidos nos anos de concepção da obra, há um atiçamento sensorial que realça os estranhamentos corpo-perceptivos do sujeito que nelas imerge. Cada cosmococa abrange um modo diferente e particular de remeter a esse lugar expresso pelos artistas.

Se na perspectiva merleau-pontiana "O corpo ele mesmo é produtor-de-lugar, trazendo ao centro lugares por meio de seus movimentos expressivos e orientacionais, é literalmente um dinamismo cinético" (CASEY, 1998, p. 236, tradução livre, grifo no original), isso significa que o circuito imaginativo e perceptivo está intricado pela expressividade da mobilidade por meio da qual lugares são realizados. Ao entrar em cada uma das cinco cosmococas, há uma experiência motriz que fornece a elas seus horizontes reversíveis de lugar. 
Entrar, imergir, interagir, pensar e sair de cada uma das cosmococas compõe, em micro-escala, uma forma de rotina corpo-espacial. De acordo com Seamon (1979, p. 55, grifos no original), "[...] uma rotina tempo-espacial é um conjunto de comportamentos habituais do corpo que se estendem por uma porção considerável de tempo". Na perspectiva do autor essa composição de rotinas decorre de uma experiência de tempo relevante, maior do que apenas um instante de interação com determinada espacialidade.

Contudo, é possível argumentar que há um comportamento similar no nível de uma escala temporal centrada no instante, como a que propõem Bachelard (2010) e MerleauPonty $(2011,2014)$. Como explica Marratto (2012, p. 56, tradução livre), para os dois fenomenólogos "[...] o tempo de nossa experiência, por assim dizer, é sempre o presente". Ao entender, portanto que rotinas espaço-temporais também podem ocorrer no microcosmo do lugar-obra, há uma dinâmica importante a ser desvelada.

As pessoas experienciam os lugares-obras das cosmococas como um coletivo de instalações que são compreendidas apenas no todo das cinco experiências. É uma situação análoga ao que Seamon (1979) conceitua como dança-de-lugar. O autor sumariza: “[...] dança-de-lugar - uma interação de várias rotinas tempo-espaciais e danças corporais enraizadas no espaço" (SEAMON, 1979, p. 56, tradução livre, grifos no original). Do mesmo modo, as cosmococas são formadas pelas micro-rotinas experienciais dos lugares-obras.

Se, como afirma Seamon, (1979, p. 57, tradução livre), "[...] a base da dança-de-lugar é o corpo-sujeito, de modo a embasar uma continuidade tempo-espacial centrada nos padrões do passado", nota-se que há contradições na adequação sumária dessa teoria para o caso de experiências mais imediatas e centradas no instante. As micro-rotinas dos corpossujeitos, ainda que também temporalmente relevantes, estão ancoradas em um nexo transitório.

O limite da implementação dessa teoria deriva do fato de que ela se ancora nas relações da tríade encontro-movimento-repouso. Particular atenção é dada por Seamon (1979) à dialética movimento-repouso. É na reciprocidade entre esses dois elementos que se estabelece a possibilidade de interpretar os padrões do passado como o fundamento para as danças-de-lugar.

Ao concordar com Bachelard (2010, p. 15) que "[...] o tempo é uma realidade encerrada no instante e suspensa entre dois nadas", entende-se que o repouso pode ser deslocado dessa tríade como uma forma de reformula-la ao contexto da experiência efêmera dos lugares-obras. Na temporalidade do instante, a dialética encontro-movimento é um campo fértil que permite compreender como existem trajetos e micro-rotinas no cerne do funcionamento perceptivo-imaginativo das cosmococas.

Pela definição de Seamon (1979, p. 99, tradução livre, grifos no original), centrado em uma temporalidade de longa duração, é entendido como "[...] encontro - qualquer situação 
de contato atento entre a pessoa e o mundo disponível'. Por meio do encontro, sujeitomundo se dinamizam na espacialização significante de onde o lugar será resultante. Ao mesmo tampo, é o encontro que media um sentido relevante pelo qual o movimento é impelido.

De acordo com Morris (2004, p. 181, tradução livre), fenomenologicamente "[...] lugar dá sentido, direção, ao nosso movimento, do mesmo modo que um quebra-cabeças parcialmente completo dá sentido as peças para ajudar-nos a encaixa-las em seus locais". O movimento, portanto, é a maneira pela qual o sentido de lugar pode ser dinamicamente constituído. Na reciprocidade com o encontro, movimento é parte integrante da possibilidade de experiência efêmera de uma micro-rotina espaço-temporal.

\section{DO BALÉ-DO-LUGAR AO BEPOP-DE-LUGAR: PRÁtICAS EFÊMERAS NAS COSMOCOCAS}

Se a dança-de-lugar concerne uma dimensão temporal orientada no passado, é necessário um reposicionamento conceitual. Ao referir-se originalmente ao place ballet, Seamon (1979) está fazendo uma correlação com a organização metódica e sistemática de coreografias e rotinas especificas a esse tipo de performance (balé). O mais adequado, na adaptação contextual aqui proposta, é a associação com uma performance que esteja aberta ao improviso e à dimensão do instante, a algo menos sistematicamente organizado: o bebop.

Como situa Monson, o bebop é um subgênero do jazz estadunidense que nasce na "[...] criação de música por meio da interação improvisada entre os sons" (MONSON, 1996, p. 2, tradução livre). Esse gênero foi popularizado por artistas como John Coltrane, Charlie Parker, Mary Lou Willians e Thelonious Monk. Ainda que existissem sequencias tradicionais e arranjos, no bebop elas poderiam ser alternadas por situações e interações improvisadas pelos grupos e/ou solistas. A mesma música, ainda que com estrutura similar, nunca é tocada igualmente duas vezes. Os ritmos são (re)construídos continuamente pela prática corporal dos músicos desse gênero (AKE, 2010; MONSON, 1996).

Os sons são compostos de maneira a realçarem a capacidade e liberdade criativa do artista que performa. De acordo com Ake (2010, p. 49, tradução livre), no bebop, "[...] a estética de improvisação pura é tão poderosa que os músicos raramente vão se gabar (ou mesmo admitir) seus esforços nesse sentido". Desse modo, são arranjos complexos que se somam num horizonte performático que combina o improviso ao encontro e movimento da música. A sinergia dinâmica desse gênero é composta pela rapidez na troca de notas e harmonias, de modo que o instante, o encontro entre os instrumentos que são mobilizados, possa reger a emergência de cada som. 
Converge-se para uma noção menos ordenada, mais aberta ao improviso e a temporalidade do que o Place ballet por meio da proposição do conceito de bebop-delugar. Se, "[...] na dança-de-lugar, rotinas individuais se encontram regularmente no tempo e no espaço. A regularidade não é intencional, ela surge lentamente no tempo como resultado de muitos encontros acidentais" (SEAMON, 1979, p. 57, tradução livre, grifo no original), no bebop-de-lugar os trajetos são incidentais, reativos aos encontros promovidos pelos movimentos e a regularidade nasce da continuidade transitória da dinâmica - improvisada ou não - do e no lugar (Figura 3).

Figura 3 - Mapa experiencial do bebop-de-lugar nas cosmococas.

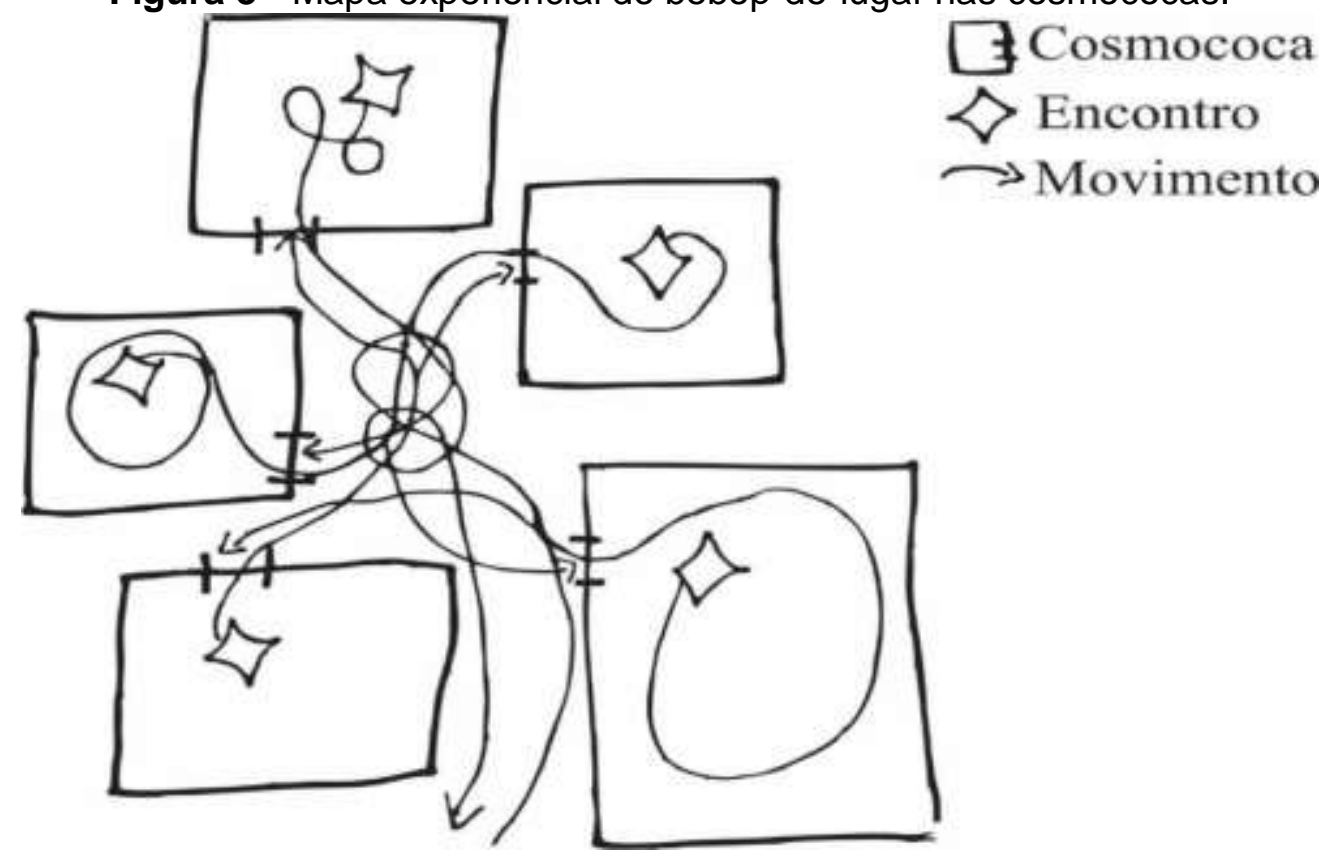

Fonte: o próprio autor, 2019.

Nas cosmococas, compreende-se que há um bebop-de-lugar na potencialidade explorativa das obras. Como sumarizado no mapa experiencial (Figura 3), o trajeto percorrido na galeria é substanciado pela dinâmica de movimento e encontro. O encontro em cada um dos lugares-obra leva ao movimento rumo ao próximo. Essa dinâmica efetivada no nível do instante e situada no horizonte da transitoriedade é crivada por um relevante nexo de improviso.

As pessoas não planejam ou refletem ativamente sobre a ordem ou a forma de imergir na galeria, elas fazem parte desse devir livre em que sujeito-obra se retroalimentam no cosmo do lugar, conforme intencionalmente arquitetado pelos artistas que projetaram a obra. Na micro-rotina corpo-espacial que decorre dessa situação, um macro-lugar experiencial relativo às cinco cosmococas é formado pela experiência do bebop-de-lugar.

Encontro e movimento se impelem em uma dinâmica em que um contrapõe e motiva o surgimento do outro. Na medida em que, como discorre Seamon (1979, p. 121-122, 
tradução livre), "[...] encontro é um refluxo e flux multifacetado de atenção", ele suscita o dinamismo daquele que imerge no lugar-obra. Ao experienciar uma cosmococa, o sujeito interage com os elementos nela presentes e posteriormente é mobilizado para buscar a outra. Ainda que possa também permanecer por um determinado tempo em uma cosmococa, sua experiência será particular porque a forma como interagirá não será coincidente com a de outro sujeito.

Partindo de Merleau-Ponty, Casey (1998, p. 229, tradução livre, grifo no original) explica que o espaço "[...] é encontrado no movimento do corpo. Para que surja um espaço, nosso corpo nele engendrado não pode permanecer estático; ele deve estar em movimento". Dessa forma, a dinâmica dialética encontro-movimento é uma mobilização sensível que decorre da corporeidade inerente ao sujeito. No bebop-de-lugar, a presentificação das micro-rotinas corpo-espaciais se conforma aos ritmos corporais de cada sujeito.

Na medida em que "[...] lugar é atingido pelo movimento" (MORRIS, 2004, p. 112, tradução livre), cada movimento entre e nas cosmococas transforma em algum nível a experiência daquele instante do lugar-obra. Os encontros promovidos nesses caminhos são fundamentos que estruturam arranjos improvisados de práticas espacializadas pelas interações com as obras.

Em Cosmococa 1 Trashiscapes (Figura 4), o movimento é interrompido por um encontro que sugere ao imergente que deite nos colchões e observe as projeções. No estranhar das navalhas, figuras cortadas e outras imagens perturbadoras que são projetadas, há uma dinâmica de confrontamento com a contradição interacional proposta. Ao mesmo tempo em que parece concernir um repouso, efetiva um encontro de desconfortos.

Pela trilha sonora variada que mistura música nordestina, rock e sons de rua, lugares são imaginativamente evocados. Esses somatórios de sentidos propositam uma interação ativa, corporal e singular para cada sujeito que imerge na obra. No contato com os objetos dispostos, sejam eles os colchões ou os travesseiros de linho em formas diversas, existem possibilidades interacionais em que o lugar-obra proposita movimentos que entrelaçam os imaginários e sensações do sujeito com a instalação.

Como pondera Grange (1985, p. 74, tradução livre) "[...] lugar, efetivamente, é intimidade por meio do mistério do corpo". É por meio dessa relacionalidade corpo-centrada que a interação com tais lugares-obras se realiza na motricidade performativa daquele que nelas imergem. A intimidade corporal faz parte do processo em que o bebop-de-lugar compõe a trajetória ativa de existência em que sujeito-obra se misturam por um somatório de circuitos perceptivos. Cada situação, cada encontro, é único, mas eles são amalgamados entre os movimentos e nuances da interação lugarizada realizada. 
Figura 4 - Hélio Oiticica e Nevile D’Almeida - Cosmococa 1 Trashiscapes (1973)

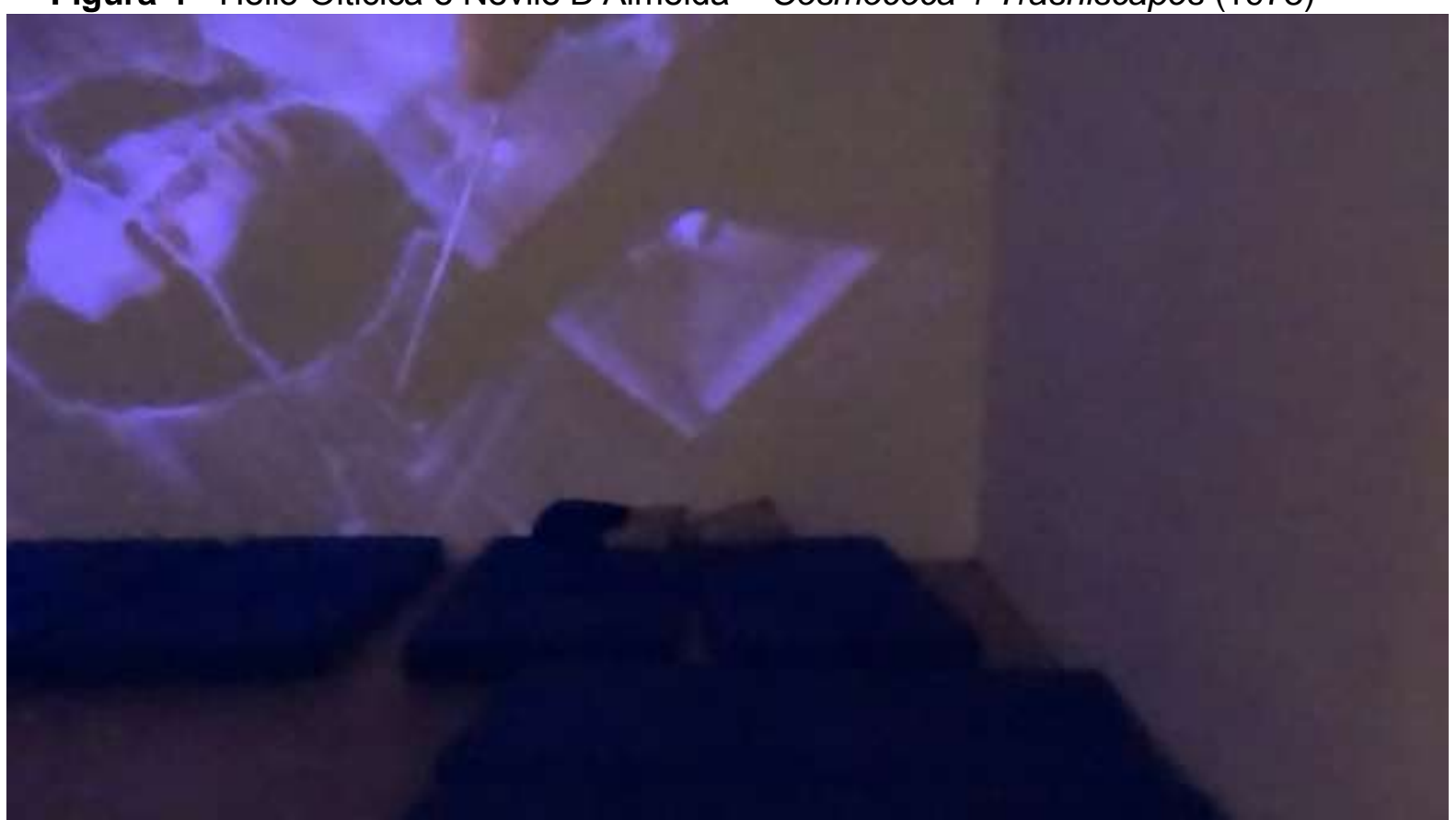

Fonte: o próprio autor, 2018.

De acordo com Barbaras (2004, p. 175, tradução livre, grifo no original), na fenomenologia Merleau-Pontiana "[...] quem percebe está no próprio lugar [au lieu] da coisa. Aquele que percebe capta a coisa apenas na medida em que é cercado por ela, imerso nela; ele faz a coisa aparecer apenas por ser adornado com a textura da coisa". As coisas, e no caso específico os lugares-obras, somente possuem significados por conta das suas texturas que compõem campos experienciais. Esses, por sua vez, agrupam núcleos que ditam o ritmo transitório - ainda que profundo - da imersão nas cosmococas.

A Cosmococa 5 Hendrix War (Figura 5) provoca encontros por meio da possibilidade de deitar-se na rede e ouvir músicas de Jimi Hendrix. Ao andar no lugar-obra, cada passo leva o sujeito para um potencial acional. A escolha de deitar ou não, qual rede escolher para ficar por um tempo ou mesmo a de somente ver e sair da sala é parte da liberdade do bebop-de-lugar. Não há uma decisão certa ou errada na dinâmica imersiva do lugar obra, mas centros atitudinais e perceptivos possíveis, de modo que ela desafia um olhar que tente decifrá-la como meramente contemplativa.

Independentemente de qualquer escolha, encontro e movimento são realizados na dinamogenia corpo-espacial dessa relação. De acordo com Relph (1976, p. 49, tradução livre), "[...] você experiencia um lugar por dentro, você está cercado por ele e é uma parte dele". A potencialidade imersiva é uma característica relevante para a definição do lugar. No horizonte de mundo pelo qual as cosmococas emergem, a Chöra define a tensão inicial que mobiliza o encontro. 
Figura 5 - Hélio Oiticica e Nevile D’Almeida - Cosmococa 5 Hendrix War (1973)

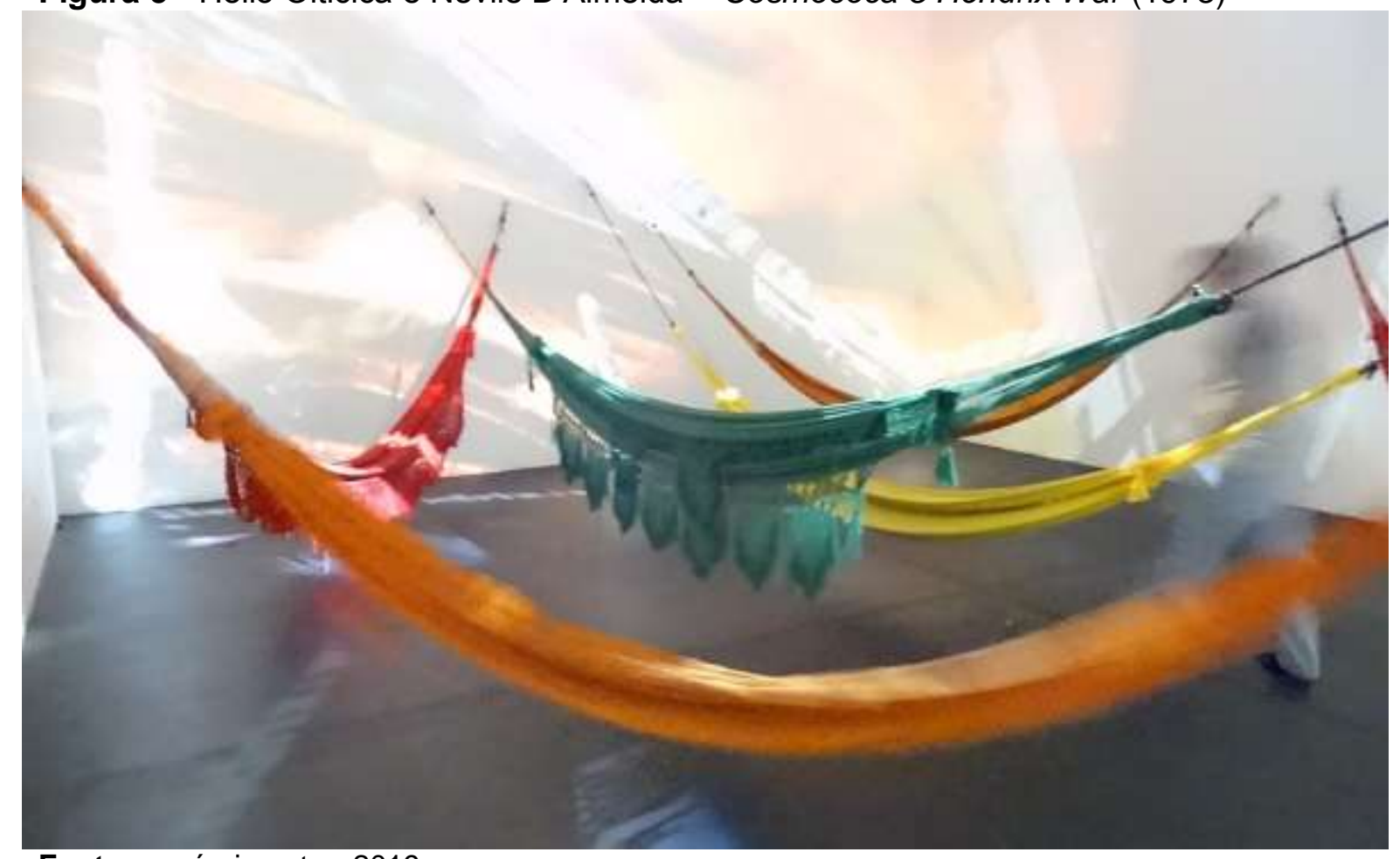

Fonte: o próprio autor, 2019.

Tato, olfato, visão e audição são evocados no bebop-de-lugar realizado na galeria cosmococa. Ressalta-se, como Moran (2013, p. 301, tradução livre), que "[...] para MerleauPonty, os fenômenos da reversibilidade e duplicidade da sensação são característicos de todas as cinco modalidades sensoriais". Cada um desses sentidos, portanto, é intrínseco na forma em que sua reversibilidade possibilita a imersão. As cosmococas exploram a reciprocidade sensorial existente em sujeito-lugar na medida em que são vivenciadas por meio do corpo.

Cosmococa 4 Nocagions (Figura 6) impele esse bebop-de-lugar no sentido de causar um primeiro estranhamento em relação a quem nela imerge. A piscina que se destaca pela iluminação na sala escura permite que o sujeito possa nadar na instalação. $A$ atividade corporal de mergulhar na obra é particularmente perturbadora porque a convergência da escuridão com a água turva e gelada dificulta a observação do fundo da piscina. O encontro, portanto, se realiza efetivamente pela experiência corporal de mergulho. As sensações se somam de modo a imergir o sujeito no lugar-obra.

Para Casey (1998, p. 204, tradução livre), “[...] cor, textura e profundidade são somente conhecidas por nós em e por meio do corpo que entra e ocupa um determinado lugar". Do mesmo modo, é somente no encontro com determinado lugar-obra por meio da experiência, imaginada ou de fato, corporificada, que se realiza uma dinâmica que tenha 
dimensões expansíveis. Nas micro-trajetórias criadas nas cosmococas, o chamado de cada obra para a interação cria esse jogo experiencial em que a sensibilidade corporal se aguça.

Figura 6 - Hélio Oiticica e Nevile D’Almeida - Cosmococa 4 Nocagions (1973)

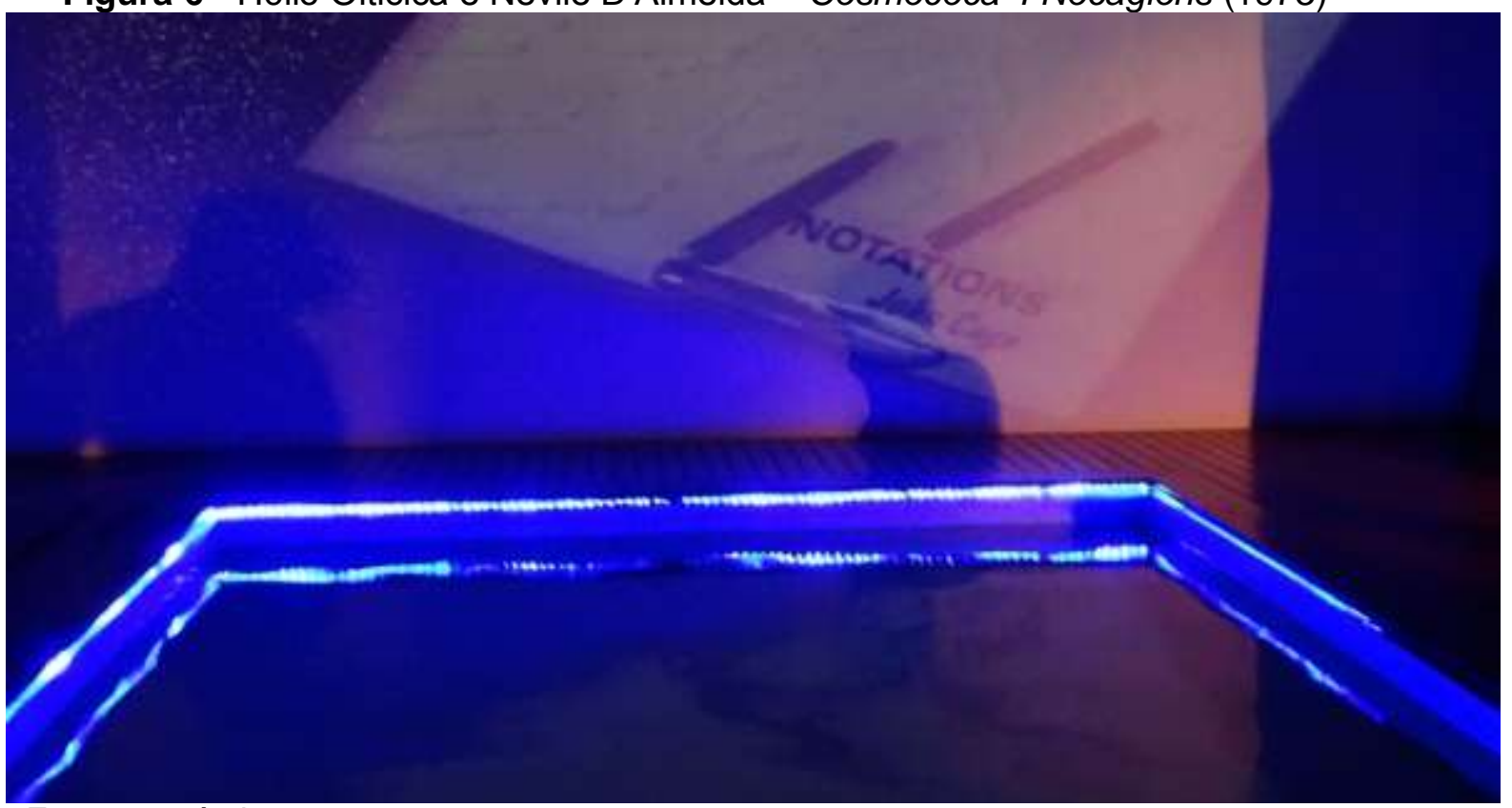

Fonte: o próprio autor, 2019.

Esse horizonte de bebop-de-lugar reverbera a centralidade dos encontros e movimentos na experiência transitória e aberta das obras. Segundo Seamon (1979, p. 101, tradução livre) "[...] um momento de encontro é integralmente relacionado a outros aspectos do momento, incluindo humor, nível de energia, experiências anteriores e conhecimento". Nesse mesmo sentido, não é possível determinar uma forma específica de dinâmica para o lugar-obra das cosmococas que seja a mesma para todas as pessoas, pois as diferentes condições dos corpos-sujeitos são os elementos projetivos de como a experiência se manifesta.

Porém, é possível pensar que elas não são as únicas obras com potencial para serem experienciadas dessa maneira. Outras instalações, ou mesmo a forma como objetos artísticos tradicionais como pinturas são expostas em salas de museus, também efetivam experiências sensoriais similares. Ao imergir nesses ambientes, há uma sensação e experimentação efetiva e relacional que dá origem à multiplicidade do bebop-de-lugar.

Se, como afirmam Davidson e Milligan (2004, p. 524, tradução livre, grifo no original), "[...] o lugar deve ser sentido para ter significado. Isso nos leva para nosso sentimento de que os sentidos significantes do espaço emergem apenas via os movimentos entre pessoas e lugares", cada experiência de bebop-de-lugar deve ser compreendida pela sua particularidade. No horizonte de como cada sujeito realiza sua trama sensível de movimento-encontro existem diferentes formas de lugares topológicos ou chöreicos. A 
percepção, portanto, nunca é realizada em relação a um dado acabado. Ela é processual na medida em que, como discorre Merleau-Ponty (2012, p. 107):

[...] ela pode ser também o reconhecimento de uma maneira de comunicar que não passa pela evidência objetiva, de uma significação que não visa um objeto já dado, mas o constitui e o inaugura, e que não é prosaica porque desperta e reconvoca por inteiro nosso poder exprimir e nosso poder de compreender.

A própria percepção é, portanto, um modo de manifestar e constituir a realização de uma determinada coisa. Pelo poder de compreensão do corpo-consciência, a substancialização da espacialidade das instalações de arte ecoa o modo como os sujeitos criam lugares em seus mundos. A experiência, em escalas tempo-espaciais diferentes, dá os contornos para as obras em suas relações com aqueles que nelas imergem.

No que se refere a arte, "[...] em acordo com um paradoxo aparente, sua criação permanece indissociável da vontade de falar sobre o mundo e, ao mesmo tempo, de uma impossibilidade de falar de outra coisa que não do mundo" (DUFOURCQ, 2012, p.298, tradução livre, grifos no original). No lugar-obra essa duplicidade é estabelecida pela forma como o mundo da instalação é relatável na medida em que ele foi construído por outro ser humano. Ele possui sentidos e nexos que foram projetados com base na espacialidade sensível de um corpo.

Durante o instante imersivo na obra de arte "[...] a subjetividade do espectador é também contida no mesmo mundo - não por projeção psicológica, mas pela habitação ou imersão nesse mundo que é ao mesmo tempo afetivo e expressivo" (CASEY, 2010, p. 4, tradução livre). Ao adentrar o lugar-obra das cosmococas, o encontro propiciado consubstancia o processo imersivo por meio do qual o corpo junta-se na amálgama sensível do bebop-de-lugar. Essa situação soma a afetividade, expressividade e Chöra das obras com o lugar topológico e experiencial dos sujeitos.

Murchadha (2015, p. 35, tradução livre) aponta que "[...] todas as coisas tomam um lugar, estão em um lugar e o lugar é o que faz delas coisas possíveis". As obras se arranjam no mundo por meio da espacialização de seus lugares. Elas somente são possíveis na condição de criações humanas que são materializadas em um determinado espaço-tempo. Simultaneamente, são núcleos por onde os sujeitos também percorrem por movimentos e encontros com lugar(es).

Corpo-ativas, as cosmococas se transcendem pela liberdade de significado que provem na interação espacial realizada em seus âmagos. Na perspectiva de Relph (1976, p. 42, tradução livre) "[...] lugares são contextos ou planos de fundo para objetos ou grupos de objetos/eventos intencionalmente definidos, assim como podem ser os próprios objetos ou eventos, ou mesmo podem ser objetos intencionais em seu próprio direito". Do mesmo 
modo, cada cosmococa é um misto de objetos intencionais e evento transitório composto como horizonte acional por onde emergem como lugares.

Bachelard (1948, p. 33, tradução livre) aborda que "[...] a imagem material é uma superação do Ser imediato, um aprofundamento do Ser superficial. E esse aprofundamento abre uma dupla perspectiva: na intimidade do sujeito atuante e dentro do interior substancial do objeto inerte que é encontrado pela percepção". Na obra de arte, esse sentido duplo de superação e aprofundamento ocorre no horizonte da lugarização. A imagem material que contextualiza a imaginação poética do sujeito que imerge na obra tem um dinamismo ativo entre interioridade e exterioridade. Reafirma-se, como Relph (1976, p. 42, tradução livre), que "[...] os lugares estão, então, incorporados nas estruturas intencionais de toda consciência e experiência humana". Mais que um objeto inerte, como apontado por Bachelard (1948), o lugar é um reencontro com o circuito ativo da percepção.

Por considerar que quem percebe é um corpo-consciência, os objetos são sempre conectados por meio de uma simbólica que os situam em relação a diferentes todos interrelacionados. Ao se mover e encontrar as cosmococas, a geografia reativa e tátil dos lugares-obras é evidenciada pela corporeidade a ela inerente. Com os pés descalços, a experiência imersiva em cada cosmococa evoca sentidos, memórias e lugares diferentes. São significativos, portanto, os elos emocionais e sensíveis efetivados no horizonte de reversibilidade em que se inserem sujeito-lugar-obra.

\section{CONSIDERAÇÕES FINAIS}

$\mathrm{Na}$ condição de experimentações corpo-sensoriais artisticamente concebidas, as cosmococas conformam uma espécie de lugar dinâmico centrado na transitoriedade de um contato significativo. Por meio da relação efetivada com o sujeito que nelas imergem, elas suscitam modos de explorar uma dinâmica de múltiplos encontros e movimentos corporais que provocam a imaginação geográfica.

Em transcendência à estabilidade das rotinas corpo-espaciais de longo prazo presentes no conceito de balé-de-lugar, a virtualidade do instante fenomênico provê a capacidade explicativa do bebop-de-lugar. Esse arranjo entrópico abarca a dimensão de improviso, imprevisto e instabilidade presente na forma de transformações relacionais que ocorrem no âmago dos lugares. Conforme vivenciado na vida hodierna, momentos de curta duração também podem marcar a história ou a memória de um determinado lugar, de modo a criar um vínculo de temporalidade incerta.

$\mathrm{Na}$ multiplicidade com que os sujeitos interagem com os espaços de suas vidas cotidianas, tal dinâmica de lugar exposta com base na obra artística pode ser expandida para as várias situações fenomênicas efêmeras. Sejam nas festas tradicionais, museus ou 
mesmo em práticas turísticas, o bebop-de-lugar oportuna um modo fenomenológico centrado no instante para desvelar as transitoriedades de determinadas manifestações de movimentos e encontros.

As cosmococas, portanto, colaboram na possibilidade de entender micro-dinâmicas de lugar no contexto dos diferentes engajamentos decorrentes de encontros-movimentos. Por meio do bebop-de-lugar explorado foi possível evidenciar como, no nível temporal do instante, a experiência de lugar efetiva expressões e interiorizações espaço-sensíveis. Esse sentido também pode ser expandido para outras situações similares em museus ou ambientes de passagem na vida cotidiana.

Como um horizonte que se desdobra da experiência particular de cada sujeito por meio de uma imersão transitória nesse ambiente, o dinamismo do bebop-de-lugar aponta para o não-planejado e incerto presente nesses espaços existenciais. No mundo contemporâneo rumo ao agravamento da crise ecológica e das mudanças climáticas, em que os ciclos da natureza estão em um momento de constante transformação, é oportuno salientar tais formas de experiência espacial.

\section{REFERÊNCIAS}

AKE, David. Jazz matters: sound, place, and time since Bebop. Berkeley: University of California Press, 2010.

ARCHER, Michael. Arte contemporânea. São Paulo: Martins Fontes, 2012.

BACHELARD, Gaston. A intuição do instante. Campinas: Verus Editora, 2010.

BACHELARD, Gaston. La terre et les rêveries de la volonté. Paris: Librairie José Corti, 1948.

BARBARAS, Renaud. The being of the phenomenon: Merleau-Ponty's ontology. Bloomington: Indiana University Press, 2004.

BUSKIRK, Martha. The contingent object of contemporary art. Cambridge: The MIT Press, 2003.

CASEY, Edward S. Aesthetic Experience. In: SEPP, Hans Rainer.; EMBREE, Lester. (org.) Handbook of phenomenological aesthetics. London: Springer Science: Bussiness Media, 2010. p. 1-7.

CASEY, Edward S. The fate of place: a philosophical history. Berkley: University of California Press, 1998.

COBB, William. Being-in-the-world and ethical language. In: CARR, David; CASEY, Edward S. (org.). Explorations in phenomenology: papers of the society for phenomenology and existential philosophy. Leiden: Martinus Nijhoff, 1973. p. 423-433.

DARDEL, Éric. O homem e a terra. São Paulo: Perspectiva, 2011.

DAVIDSON, Joyce; MILLIGAN, Christine. Embodying emotion sensing space: introducing emotional geographies. Social \& Cultural Geography, London, UK, v. 5, n. 4, p. 523-532, 2004.

DUFOURCQ, Annabelle. Merleau-Ponty: une ontologie de l'imaginaire. New York: Springer, 2012. 
DUNPHY-BOMFIELD, Jocelyn. Harmony in a Dislocated World. In: CATALDI, Suzanne L.; HAMRICK, William S. (orgs.). Merleau-Ponty and environmental philosophy: Dwelling on the landscapes of though. New York: State University of New York Press, 2007. p. 217-234.

GRANGE, Joseph. Place, body and situation. In: SEAMON, David; MUGERAUER, Robert. (orgs.). Dwelling, place and environment: towards a phenomenology of person and world. Dordrecht: Martinus Nijhoff Publishers, 1985. p. 71-85.

HAWKINS, Harriet. Dialogues and Doings: Sketching the Relationships between Geography and Art. Geography Compass, Oxford, OX, v. 5, n. 7, p. 464-478, 2011.

HAWKINS, Harriet. For creative geographies: geography, visual arts and the making of worlds. Routledge: London, 2014.

KARJALAINEN, Pauli Tapani. Place in Urwind: a humanist geography view.

Geograficidade, Niterói, RJ, v. 2, n. 2, p. 4-22, inverno 2012.

KAUSHIK, Rajiv. Art and institution: aesthetics in the late works of Merleau-Ponty. London: Continuum International Publishing Group, 2011.

LAGO, Pedro Corrêa do. A acolhida internacional da arte brasileira. In: SARDENBERG,

Ricardo (org.). Arte contemporânea no século XXI: 10 brasileiros no circuito internacional. Rio de Janeiro, RJ: Capivara, 2011. p. 7-13.

LARSEN, Soren C.; JOHNSON, Jay. T. Toward an open sense of place: Phenomenology, affinity, and the question of being. Annals of the Association of American Geographers, Washington, US, v. 102, n. 3, p. 632-646, 2012.

MARRATTO, Scott L. The intercorporeal self: Merleau-Ponty on subjectivity. Albany: State University of New York Press, 2012.

MCDUFFIE, Michael F. Art as an enclave of meaning. In: CROWELL, Steven G. (org.). The prism of the self: philosophical essays in honor of Maurice Natason. Dordrecht, NL: Springer, 1995. p. 205-220.

MERLEAU-PONTY, Maurice. A prosa do mundo. São Paulo: Cosac Naify, 2012. MERLEAU-PONTY, Maurice. Fenomenologia da percepção. São Paulo: Martins Fontes, 2011.

MERLEAU-PONTY, Maurice. O olho e o espírito. São Paulo: Cosac Naify, 2013. MERLEAU-PONTY, Maurice. O visível e o invisível. São Paulo: Perspectiva, 2014.

MONSON, I. Saying something: Jazz improvisation and interaction. Chicago: The University of Chicago Press, 1996.

MORAN, D. The phenomenology of embodiment: Intertwining and Reflexivity. In: JENSEN, R. T.; MORAN, D. The phenomenology of embodied subjectivity. New York: Springer: 2013. p. 285-304.

MORRIS, D. The sense of space. Albany: State University of New York Press, 2004.

MURCHADHA, F. Ó. Space, time and the articulation of a place in the world: the philosophical context. In: RICHARDSON, B. (org.). Spatiality and symbolic expression: on the links between place and culture. New York: Palgrave Macmillan, 2015. p. 21-40.

RAMÍREZ, M. T. Creativity. In: SEPP, H. R.; EMBREE, L. (Orgs.) Handbook of phenomenological aesthetics. London: Springer Science+Bussiness Media, 2010. pp.5761.

RELPH, E. Place and placelessness. London: Pion, 1976. 
SARDENBERG, R. Inserções em circuitos internacionais. In: SARDENBERG, R. (org.). Arte contemporânea no século XXI: 10 brasileiros no circuito internacional. Rio de Janeiro, RJ: Capivara, 2011. p. 15-23.

SEAMON, D. A geography of the lifeworld: movement, rest and encounter. London: Croom Helm, 1979.

SEAMON, D. Place attachment and phenomenology: The synergistic dynamism of place. In: MANZO, L. C.; DEVINE-WRIGHT, P. (org.). Place attachment: advances in theory, methods and applications. Abingdon: Routledge, 2014. p. 11-22.

SILVA, A. C. De quem é o pedaço? São Paulo: Hucitec, 1986.

TUAN, Y. Espaço e lugar: a perspectiva da experiência. Londrina: EdUel, 2013.

TUAN, Y. Humanist geography: an individual's search for meaning. Staunton: George F. Thompson Publishing, 2012.

TUNGA, B. M. Entrevista. [Entrevista concedida a] Pedro Corrêa do Lago. SARDENBERG, R. (org.). Arte contemporânea no século XXI: 10 brasileiros no circuito internacional. Rio de Janeiro: Capivara, 2011. p. 120-143.

Recebido: abril de 2020. Aceito: julho de 2020. 